\title{
Recurrent Priapism in Adolescent with Sickle Cell Anemia: What to do?
}

\author{
Ligia Yumi Suzuki Moitinho ${ }^{1}$, Lívia Fratelli ${ }^{1}$, \\ Lívia Tomita Gonçalves ${ }^{1}$, Gabriel de Azambuja Beigin ${ }^{2}$, \\ Luis Cesar Fava Spessoto ${ }^{3}$, Fernando Nestor Facio Junior ${ }^{3}$
}

${ }^{1}$ Graduate Student, School of Medicine (FAMERP), São José do Rio Preto, SP, Brazil

${ }^{2}$ Urology Resident Student, School of Medicine (FAMERP), São José do Rio Preto, SP, Brazil

${ }^{3}$ Profes s or of Urology, Department of Urology, School of Medicine (FAMERP/FUNFARME), São José do Rio Preto, SP, Brazil

\begin{abstract}
In this report, we present a case of an adolescent with sickle cell anemia and a history of recurring ischemic priapism. Thirty-two hours after the onset of priapis $\mathrm{m}$, the patient was submitted to drainage, washing with an adrenaline solution, local ice, a non-steroidal antiinflammatory drug and tadalafil ( $5 \mathrm{mg}$ /day). However, However, tumescence remained and corpus cavernosum-corpus spongiosum shunt was performed. Such patients should be treated at a specialized medical center to avoid complications, such as diminished erectile function and dissatisfaction with one's sex life in the future. Although the early implantation of a penile prosthesis can avoid further e pisodes of priapism, there is no consensus in the literature on the indication of a penile implant for individuals less than 18 years of age.
\end{abstract}

Keywords: Priapism, Ischemic Priapism, Sickle Cell Anemia, Penile Prosthesis, Corpus Cavernosum-Corpus Spongiosum Shunt

\section{Introduction}

Priapism is a urological emergency characterized by prolonged penile erection in the absence of sexual interest or desire. This condition is classified based on the degree of blood oxygenation in the corpus cavernosum as low flow (ischemic) or high flow (non-ischemic) priapism. ${ }^{1-4}$ Causes include sickle cell anemia, intracavernosal injection of vasoactive drugs and the use of recreational drugs. ${ }^{4}$

The physiopathology of ischemic priapism consists of a reduction or obstruction of penial arterial blood flow caused by high pressure in the veins of the corpora cavernosa, leading to progressive ischemia, hypoxia, hypercapnia and acidosis in the smooth muscle of the corpus cavernosum. ${ }^{3}$ The degree of damage to erectile tissue is determined by the duration of the ischemia, which, when prolonged, can result in tissue necrosis." 6 Thus, ischemic priapism can be considered a form of compartment syndrome. ${ }^{5}$ Tissue necrosis may be accompanied by refractory erectile dysfunction and penile shortening due to the replacement of the necrosed tissue of the erectile bodies with fibrotic tissue. ${ }^{5,6}$

The duration of the episodes is the most significant predictor of adequate erectile function in the future. Interventions should be initiated from four to six hours, focusing on detumescence, the reduction in pain and prevention of erectile dysfunction. ${ }^{1}$

\section{Clinical Case}

A 17-year-old patient with sickle cell anemia and a history of episodes of priapism presented with coryza, tearing of the eyes, sore throat, retro-orbital pain, headache, cough, fever and bodily pain. After 10 days, the patient sought a healthcare service due to the worsening of the condition, with strong, constant pain in the lower limbs, dorsum and thorax. Infection by COVID-19 was confirmed. The patient was admitted to hospital the same day, when he suddenly developed priapism that initiated with edema, redness and heat and evolved with pain, dysuria, oliguria and pain in the hypogastrium.

Thirty-two hours from the onset of priapism, the patient was submitted to two drainages of the corpus cavernosum, with the removal of approximately 50 $\mathrm{ml}$ of blood for laboratory analysis. Noradrenaline was administered without detumescence. The patient was then sent to the urology service of a university hospital located in the state of São Paulo, Brazil, where arterial blood gas and lactate exams confirmed ischemic priapism. The patient was submitted to drainage, washing with an adrenaline solution, local ice, a non-steroidal anti-inflammatory drug and tadalafil ( $5 \mathrm{mg} /$ day). However, tumescence remained and corpus cavernosum-corpus spongiosum shunt was performed (Figure 1). 


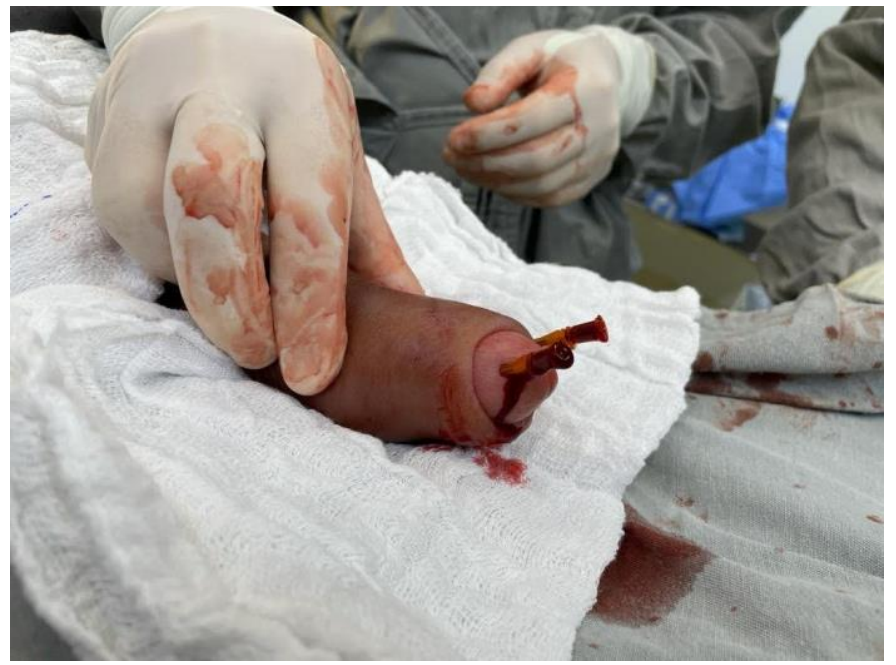

Figure 1. Corpus cavernosum-corpus spongiosumshunt surgery

\section{Discussion}

This case report is relevant due to the need for a rapid, precise diagnosis and adequate treatment for a clinical outcome with a better quality of life in the future for a young patient with sickle cell anemia and recurrent priapism.

The initial, less invasive measures are the drainage of blood from the corpus cavernosum with or without irrigation $^{2}$ and the use of an intracavernal injection of a sympathomimetic agent. ${ }^{1}$ The failure of these measures indicates the occurrence of irreversible smooth muscle changes of the corpus cavernosum, which is expected in a prolonged episode, as in the case presented herein. ${ }^{7,8}$

When priapism lasts approximately $36 \mathrm{~h}$, the correct conduct is a shunt to achieve detumescence, which does not avoid clinically refractory erectile dysfunction, as necrosis has likely already occurred. ${ }^{9}$ At this point, the need for a penile prosthesis is considered. A prosthesis may be the treatment of choice after unsuccessful shunt surgery, ${ }^{7}$ which can be done immediately or at a subsequent date. The placement a prosthesis during the acute condition is an easier procedure, as the fibrosis is not yet throughout the entire cavernous tissue. ${ }^{7}$ However, the risk of infection exists, especially when shunt surgery had been performed, as occurred in the present case. Thus, it is advisable to wait a few days to treat the edema, hematoma and bacterial contamination..$^{10}$ In the present case, the patient is a minor and, according to Brazilian law, requires authorization from a legal guardian. There is no consensus in the literature on the indication for a penile prothesis in this age group.

\section{Conclusion}

Patients with recurrent priapism should be treated at a specialized medical center to avoid complications, such as diminished erectile function and dissatisfaction with one's sex life in the future. Although the early implantation of a penile prosthesis can avoid further episodes of priapism, there is no consensus in the literature on the indication of a penile implant for individuals less than 18 years of age. This underscores the need for discussion in specialized forums regarding the best conduct for adolescents with sickle cell anemia and recurrent priapism.

\section{References}

1- Salonia A, Eardley I, Giuliano F, et al. European Association of Urology guidelines on priapis m. Eur Urol 2014;65:480489. https://doi.org/10.1016/j.eururo.2013.11.008

2- Montague DK, Jarow J, Broderick GA, et al. American Urological Association guideline on the management of $\begin{array}{lllll}\text { priapis } m . \quad \mathrm{J} & \text { Urol } & 2003 ; 170(4 & \mathrm{Pt} & 1): 1318-1324\end{array}$ https://doi.org/10.1097/01.ju.0000087608.07371.ca

3- Broderick GA, Kadioglu A, Bivalacqua TJ, et al. Priapism: Pathogenesis, epidemiology, and management. J Sex Med 2010;7(1 Pt 2):476-500. https:// doi: 10.1111/i.17436109.2009.01625.x

4- Rees RW, Kalsi J, Minhas S, et al. The management of lowflow priapis $\mathrm{m}$ with the immediate insertion of a penile prosthesis. BJU Int 2002;90:893-897. https://doi.org/10.1046/i.1464-410x.2002.03058.x

5- Capece M, Gillo A, Cocci A, et al. Management of refractory ischemic priapis m: Current perspectives. Res Rep Urol 2017; 9:175-179. https://doi.org/10.2147/rru.s 128003

6- Anele UA, Morrison BF, Burnett AL. Molecular pathophysiology of priapism: Emerg ing targets. Curr Drug Targets 2015; 16:474-483 https://doi.org/10.2174/1389450115666141111111842

7- Yücel ÖB, Pazir Y, Kadioglu A. Penile prosthesis implantation in priapism. Sex Med Rev 2018;6:310-318 https://doi.org/10.1016/i.s xmr.2017.08.002

8- Levey HR, Kutlu O, Bivalacqua TJ. Medical management of ischemic stuttering priapism: A contemporary review of the literature. Asian J Androl 2012;14:156-163. https://doi.org/10.1038/aja.2011.114

9- Capece M, La Rocca R, Mirone V, Bivalacqua TJ, Castiglione F, Albersen M, Ralph DJ, Muneer A, Garaffa G. A Systematic Review on Ischemic Priapism and Immediate Implantation: Do We Need More Data? Sex Med Rev. 2019 Jul;7(3):530-534. https://doi.org/10.1016/j.s xmr.2018.10.007

10- Ralph DJ, Garaffa G, Muneer A, et al. The immediate insertion of a penile prosthesis for acute ischaemic priapis $\mathrm{m}$. Eur Urol 2009;56:1033-10 https ://doi.org/10.1016/j.eururo.2008.09.044 